Article

\title{
Assessing the Effect of Modifying Milking Routines on Dairy Farm Economic and Environmental Performance
}

\author{
Michael Breen ${ }^{1, *}$, Michael D. Murphy ${ }^{2}$ and John Upton $^{3}$ \\ 1 Department of Mechanical, Biomedical and Manufacturing Engineering, Munster Technological University, \\ Cork T12 P928, Ireland \\ 2 Department of Process, Energy and Transport Engineering, Munster Technological University, \\ Cork T12 P928, Ireland; michaeld.murphy@cit.ie \\ 3 Teagasc, Animal \& Grassland Research and Innovation Centre, Moorepark, Fermoy P61 C996, Ireland; \\ john.upton@teagasc.ie \\ * Correspondence: michael.breen@cit.ie
}

Citation: Breen, M.; Murphy, M.D.; Upton, J. Assessing the Effect of Modifying Milking Routines on Dairy Farm Economic and Environmental Performance. AgriEngineering 2021, 3, 266-277. https://doi.org/10.3390/ agriengineering 3020018

Academic Editor: Travis Esau

Received: 1 April 2021

Accepted: 14 May 2021

Published: 18 May 2021

Publisher's Note: MDPI stays neutral with regard to jurisdictional claims in published maps and institutional affiliations.

Copyright: () 2021 by the authors. Licensee MDPI, Basel, Switzerland. This article is an open access article distributed under the terms and conditions of the Creative Commons Attribution (CC BY) license (https:// creativecommons.org/licenses/by/ $4.0 /)$.

\begin{abstract}
The objective of this paper was to quantify the economic and environmental effects of changing a dairy farm's milking start times. Changing morning and evening milking start times could reduce both electricity costs and farm electricity related $\mathrm{CO}_{2}$ emissions. However, this may also involve altering farmer routines which are based on practical considerations. Hence, these changes need to be quantified both in terms of profit/emissions and in terms of how far these milking start times deviate from normal operations. The method presented in this paper optimized the combination of dairy farm infrastructure setup and morning and evening milking start times, based on a weighting variable $(\alpha)$ which assigned relative importance to labor utilization, farm net profit and farm electricity related $\mathrm{CO}_{2}$ emissions. Multi-objective optimization was utilized to assess trade-offs between labor utilization and net profit, as well as labor utilization and electricity related $\mathrm{CO}_{2}$ emissions. For a case study involving a 195 cow Irish dairy farm, when the relative importance of maximizing farm net profit or minimizing farm electricity related $\mathrm{CO}_{2}$ emissions was high, the least common milking start times (06:00 and 20:00) were selected. When the relative importance of labor utilization was high, the most common milking start times (07:00 and 17:00) were selected. The 195 cow farm saved $€ 137$ per annum when milking start times were changed from the most common to the least common. Reductions in electricity related $\mathrm{CO}_{2}$ emissions were also seen when the milking start times were changed from most common to least common. However, this reduction in emissions was primarily due to the addition of efficient and renewable technology to the farm. It was deduced that the monetary and environmental benefits of altering farmer milking routines were unlikely to change normal farm operating procedures.
\end{abstract}

Keywords: dairy; milking start times; profitability; emissions; optimization; sustainable energy

\section{Introduction}

Since European Union milk quota abolition, milk output from Irish dairy farms has increased significantly, with the amount of milk produced in Ireland from the beginning of 2015 to the beginning of 2021 increasing by $46.8 \%$ [1]. This increase has occurred at a time where Ireland's national obligation to reduce greenhouse gas (GHG) emissions has become more prevalent. The Irish department of agriculture has targeted a $20 \%$ reduction in agricultural energy use and at least $20 \%$ deployment of renewable energy technologies in the agricultural sector by 2030 [2]. The aforementioned increase in milk production may lead to higher dairy farm GHG emissions and electricity costs [3]. Modifying farmer behavior by changing morning and evening milking start times could potentially reduce both electricity costs and GHG emissions [4]. However, these reductions would involve altering deeply engrained farmer working routines. Hence, it is necessary to quantify any potential savings in electricity costs and electricity related $\mathrm{CO}_{2}$ emissions associated with 
adjustments in milking start times, while also understanding the trade-offs between labor utilization, profitability and emissions.

A previous study by Upton et al. [4] demonstrated that adjusting morning and evening milking start times could reduce total annual farm electricity costs by between $5 \%$ and $39 \%$, depending on the size of farm and electricity tariff used. The milking start times which resulted in the largest annual electricity cost reductions were 5:00 and 20:00 for morning and evening milking, respectively. However, using these milking start times may necessitate significant changes to a farmer's routine. This was demonstrated by a study of 37 dairy farms [5] which showed that no morning milking started before 5:30, while less than $5 \%$ of evening milkings started between 19:30 and 20:00, with none starting after 20:00. These results imply that very early morning milking start times and very late evening milking start times are not common for the majority of farmers.

Previous research by Breen et al. [6] showed that to maximize return on investment in dairy farm infrastructure, the optimal morning and evening milking start times were 5:00 and 20:00, respectively. However, the feasibility of using these milking start times was not considered as the optimization was purely financial. A study by Remond et al. [7] defined the normal milking interval ranges to be between 10:14 (i.e., $10 \mathrm{~h}$ from morning to evening milking and $14 \mathrm{~h}$ from evening to morning milking) and 12:12 for twice-daily milking. Other studies involving twice-daily milking [8-13] reported a similar range of milking intervals.

No previous studies have investigated the optimization of dairy farm infrastructure setup and milking start times while also considering the associated economic and environmental impacts. The objective of this study was to carry out multi-objective optimization of milking start times and farm infrastructure setup to evaluate trade-offs between labor utilization, farm profitability and farm electricity related $\mathrm{CO}_{2}$ emissions.

\section{Materials and Methods}

\subsection{Overview}

Multi-objective optimization was employed in this paper to obtain the optimal milking start times and farm infrastructure setup to maximize a labor utilization function (LUF) while either maximizing farm net profit or minimizing farm electricity related $\mathrm{CO}_{2}$ emissions, based on a weighting variable $(\alpha)$. An illustration of the methodology can be seen in Figure 1. 


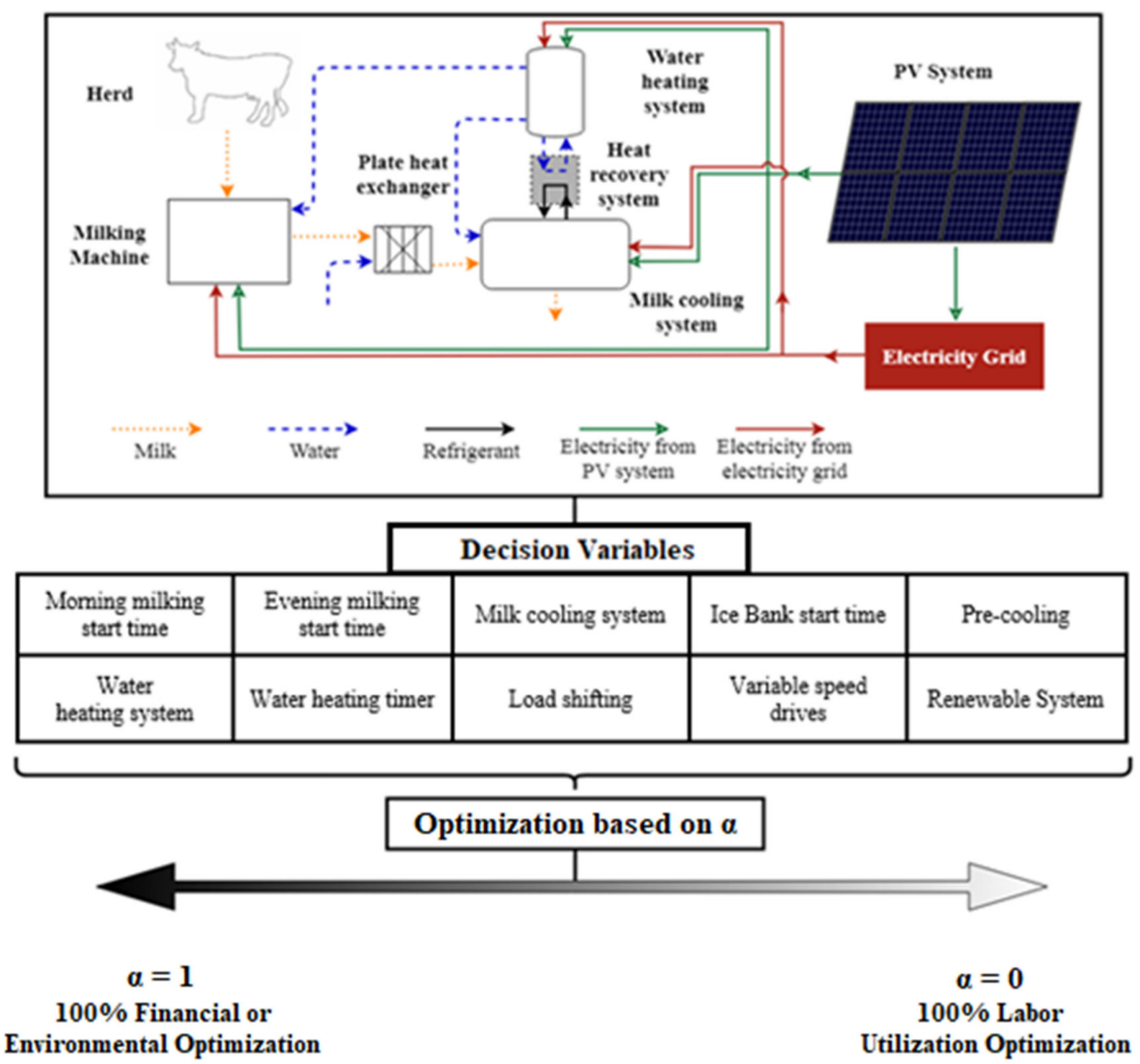

Figure 1. Schematic of methodology employed. The optimal farm setup to maximize labor utilization, while also either maximizing profit or minimizing electricity related $\mathrm{CO}_{2}$ emissions was found.

\subsection{Modelling of Labor Utilization Function (LUF)}

\subsubsection{Data Collection for Milking Start Time Distributions}

This paper employed a LUF to allow different combinations of morning and evening milking start times to be assessed under the criterion of how far these combinations deviated from normal operations. To create the LUF, the distributions of morning and evening milking start times for a selection of dairy farms were calculated. These distributions provided information regarding the most and least common milking start times used by dairy farmers. The most common milking start times were considered "normal operations" for the purpose of this study. The LUF then quantified how far particular morning and evening milking start time combinations deviated from normal operations. Data were collected from 46 dairy farms between April and October 2016 inclusive. Run-time meters were fitted to the vacuum pumps in the milking parlor and data relating to electricity consumption of the vacuum pumps were recorded every $15 \mathrm{~min}$. Hence, the milking start times could be inferred from this data. However, the data did not encompass other tasks associated with milking that occur when the milking machines are turned off. All farms provided at least 70 recordings relating to milking start times. Some farms contributed 
more data points than others and hence the average morning and evening milking start times between April and October 2016 were calculated for each farm.

\subsubsection{LUF Development}

The LUF was developed based on the data described in Section 2.2.1. Since this study considered twice-daily milking, two separate functions for morning milking and evening milking were used, known as the morning labor utilization function (MLUF) and evening labor utilization function (ELUF). These were then combined to create the LUF for specific pairs of morning and evening milking start times. The MLUF and ELUF are described in Sections 2.2.3 and 2.2.4.

\subsubsection{Morning Labor Utilization Function (MLUF)}

A histogram was created to illustrate the distribution of morning milking start times for the 46 farms (Figure 2). The MLUF was then fitted to these data using the curve fitting toolbox in MATLAB 2015a. A Gaussian model fitted using nonlinear least squares was found to be the most suitable for the data. The equation for the MLUF was as follows:

$$
\operatorname{MLUF}\left(M T_{m}\right)=\mathrm{ae}^{-\frac{\left(M T_{m}-b\right)^{2}}{2 c^{2}}}
$$

where $\operatorname{MLUF}\left(M T_{m}\right)$-Morning labor utilization function for a particular morning milking start time $M T_{m}, a=24.50, b=7.31, c=0.67$.

The MLUF is shown in Figure 2 along with the morning milking start time distribution histogram.

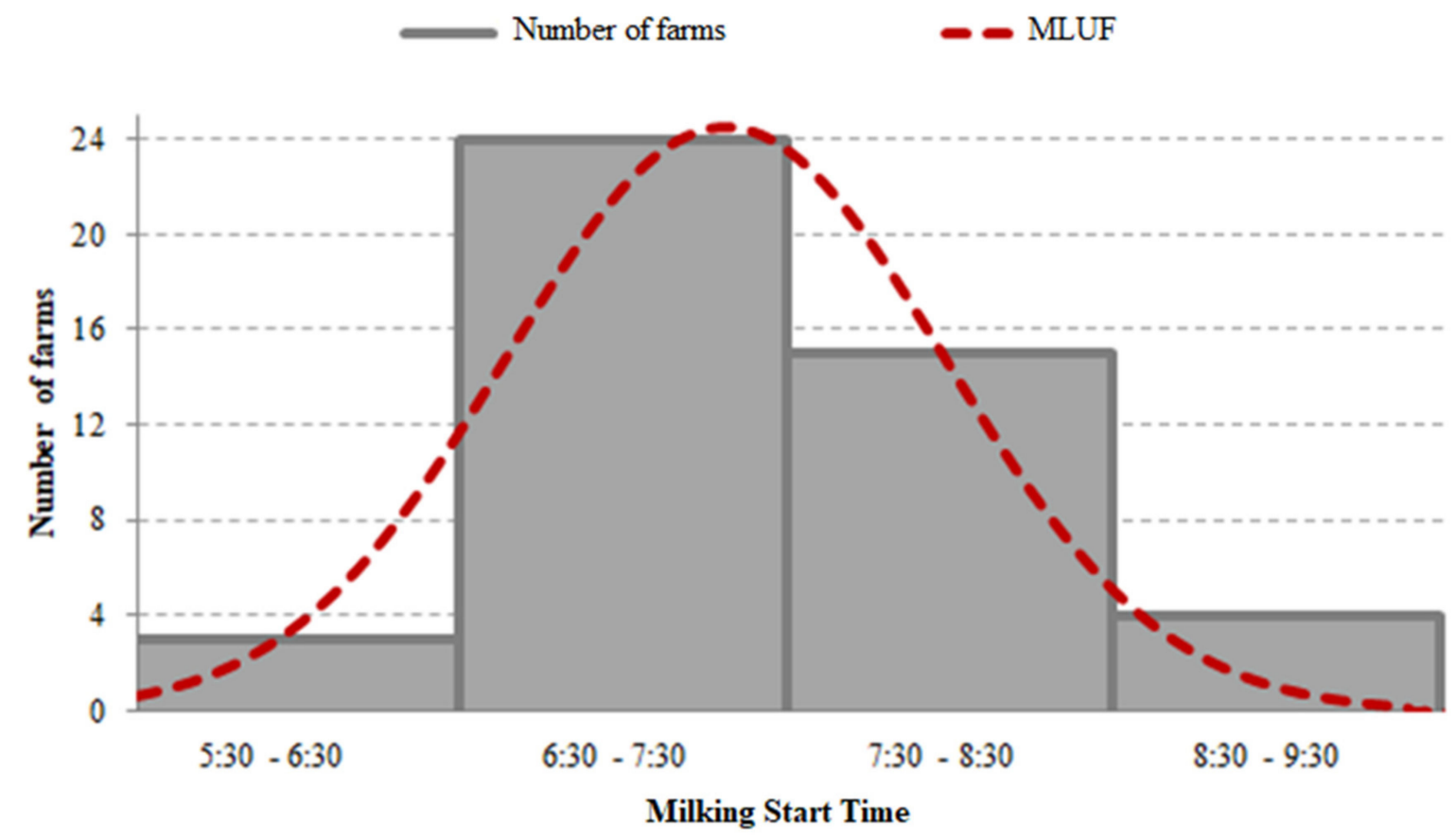

Figure 2. Distribution of morning milking start times for the 46 farms used in this study. The morning labor utilization function (MLUF) is also shown.

\subsubsection{Evening Labor Utilization Function (ELUF)}

A histogram was created to illustrate the distribution of evening milking start times for the 46 farms (Figure 3). The ELUF was then fitted to these data using the curve fitting toolbox in MATLAB 2015a. A two-term Fourier model fitted using nonlinear least squares was found to be the most suitable for the data. The equation for the ELUF was as follows: 


$$
\operatorname{ELUF}\left(M T_{e}\right)=c_{0}+c_{1} \cos \left(w M T_{e}\right)+d_{1} \sin \left(w M T_{e}\right)+c_{2} \cos \left(2 w M T_{e}\right)+d_{2} \sin \left(2 w M T_{e}\right)
$$

where $\operatorname{ELUF}\left(M T_{e}\right)$-Evening Labor Utilization Function for a particular evening milking start time $M T_{e}, c_{0}=-10.23, c_{1}=20.62, w=0.75, d_{1}=27.17, c_{2}=12.06$ and $d_{2}=-8.97$.

The ELUF is shown in Figure 3 along with the evening milking start time distribution histogram.

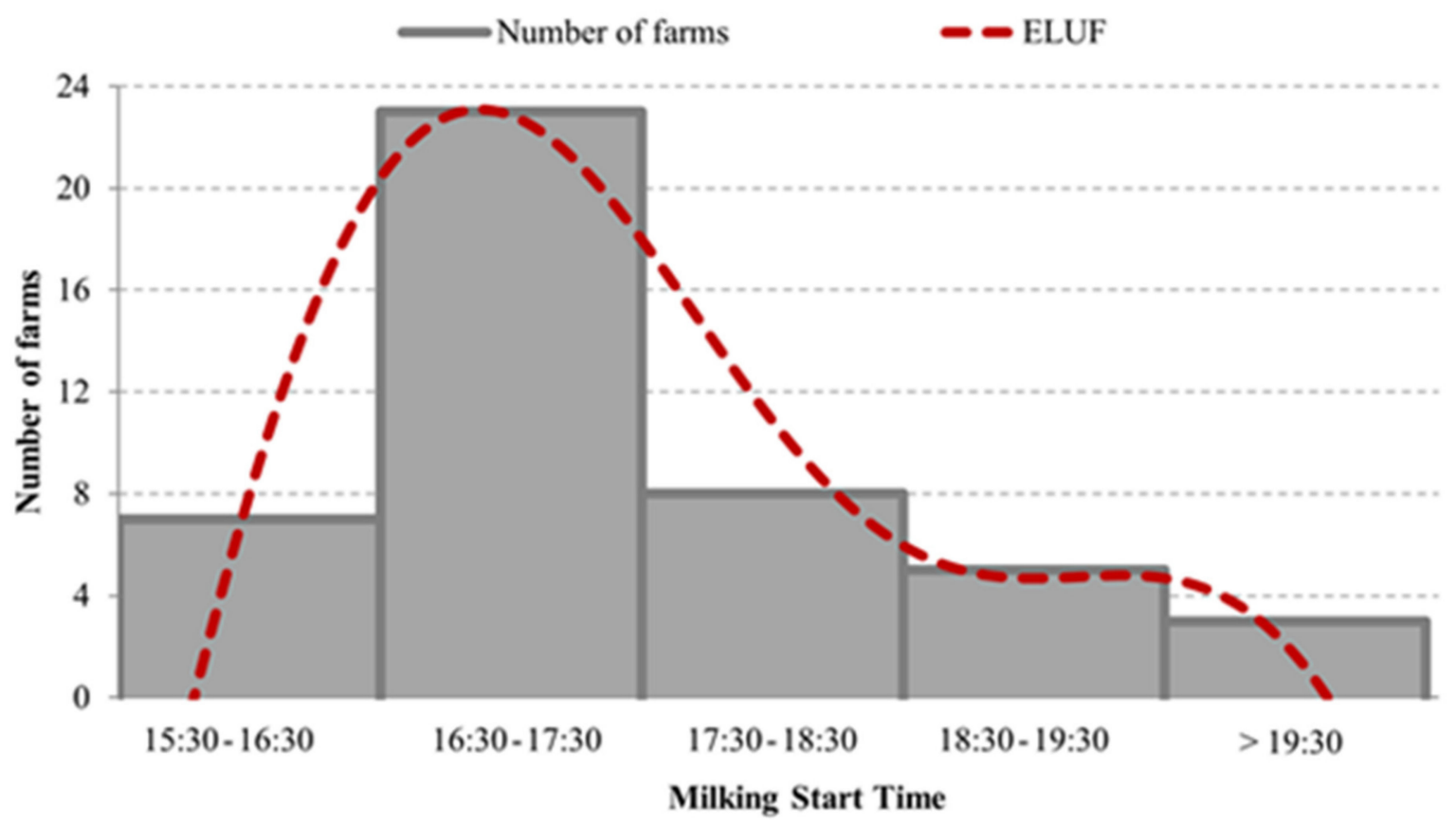

Figure 3. Distribution of evening milking start times for the 46 farms used in this study. The evening labor utilization function (ELUF) is also shown.

Using the MLUF and ELUF from Equations (1) and (2), and normalizing both to a value between 0 and 100, the LUF for a particular morning and evening milking start time combination was defined as follows:

$$
\operatorname{LUF}\left(M T_{m}, M T_{e}\right)=\frac{\operatorname{MLUF}\left(M T_{m}\right)+\operatorname{ELUF}\left(M T_{e}\right)}{2}
$$

where $\operatorname{LUF}\left(M T_{m}, M T_{e}\right)$-Labor utilization function for morning milking start time $M_{m}$ and evening milking start time $M_{e}, \operatorname{MLUF}\left(M T_{m}\right)$-Morning labor utilization function for morning milking start time $M T_{m}, \operatorname{ELUF}\left(M T_{e}\right)$-Evening labor utilization function for evening milking start time $M T_{e}$.

\subsection{Optimization}

\subsubsection{Implementation of Multi-Objective Optimization}

The weighted sum method was used to transform multiple objectives into one objective [14-22]. This method has been deployed previously for similar applications by Breen et al. $[23,24]$. In this study, three criteria were considered for multi-objective optimization. The labor utilization criterion considered was the LUF (Equation (3)), the economic criterion was the annual farm after-tax net profit (ATNP), and the environmental criterion was the annual farm electricity related $\mathrm{CO}_{2}$ emissions $(\mathrm{CE})$.

The process for evaluating the profitability of different milking start times and farm infrastructure setup was previously described in Breen et al. [6]. The annual electricity use of a dairy farm with an infrastructure and management setup was defined using 46 different variables and calculated using the model for electricity consumption on dairy farms (MECD) [3]. These variables related to areas such as milk cooling, water heating, 
vacuum pumps, lighting and scrapers. The net profit of the farm was then calculated using farm economic performance data and equipment investment costs. Further details on the 46 variables used to describe the farm are detailed in Breen et al. [6,24]. Farm environmental performance in terms of electricity related $\mathrm{CO}_{2}$ emissions was computed using the procedure previously employed by Breen et al. [24]. The electricity consumption of the farm, represented by a $12 \times 24$ matrix calculated using the MECD, was multiplied by emission factors which quantified the amount of $\mathrm{CO}_{2}$ emitted per $\mathrm{kWh}$ of electricity used. These emission factors varied hour to hour, day to day and month to month. It should be noted that the electricity related $\mathrm{CO}_{2}$ emissions used in this study represented mixed emissions and did not consider marginal emissions.

\subsubsection{Decision Variables}

Decision variables employed in this study included morning milking start time $\left(\mathrm{MT}_{\mathrm{m}}\right)$, evening milking start time $\left(\mathrm{MT}_{\mathrm{e}}\right)$, milk cooling system (MCS), ice bank start time $\left(\mathrm{T}_{\mathrm{ib}}\right)$, pre-cooling (PC), water heating system (WHS), water heating timer (WHT), load shifting (LS), variable speed drives (VSD), and renewable system (RS). For more details on MCS, $\mathrm{T}_{\mathrm{ib}}, \mathrm{PC}, \mathrm{WHS}, \mathrm{WHT}, \mathrm{LS}$ and VSD please refer to Breen et al. $[6,23,24]$. The remaining three decision variables $\left(\mathrm{MT}_{\mathrm{m}}, \mathrm{MT}_{\mathrm{e}}\right.$, and $\left.\mathrm{RS}\right)$ are described below:

- Morning milking start time $\left(\mathrm{MT}_{\mathrm{m}}\right)$-Four options were considered, in hourly increments from 6:00 to 9:00 inclusive in order to reflect the measured distribution of morning milking start times (Figure 2).

- Evening milking start time $\left(\mathrm{MT}_{\mathrm{e}}\right)$-Five options were considered in hourly increments from 16:00 to 20:00 inclusive in order to reflect the measured distribution of evening milking start times (Figure 3).

- $\quad$ Renewable system (RS)-Based on the authors' previous studies, three renewable systems were considered, namely photovoltaic (PV) systems, solar thermal water heating systems and heat recovery systems. In total, there were 13 possible options for this decision variable:

- $\quad$ Six PV system sizes-2, 4, 6, 8, 10, and $11 \mathrm{kWp}$ [23].

- Five solar thermal water heating system sizes-2, 4, 6, 8, and $10 \mathrm{~m}^{2}$ [24].

- One scenario in which heat recovery was used on the farm [24].

- One scenario in which no renewable systems were used on the farm.

\subsubsection{Objective Function}

Three objective functions $(\mathrm{A}, \mathrm{B}, \mathrm{C})$ were used for multi-objective optimization in this study:

$$
\begin{gathered}
\text { Objective function } A: \text { Maximize } \operatorname{LUF}(x) \\
\text { Objective function } B: \text { Maximize ATNP }(x) \\
\text { Objective function } C: \text { Minimize CE }(x)
\end{gathered}
$$

where $x$-Vector of the decision variables, $\operatorname{LUF}(x)$-Labor utilization function using $x$ decision variables, $\operatorname{ATNP}(x)$-Average annual after-tax net profit during the defined time horizon using $x$ decision variables, and $\mathrm{CE}(x)$-Annual farm electricity related $\mathrm{CO}_{2}$ emissions during the defined time horizon using $x$ decision variables.

The weighted objective function $J(x)$ describes the trade-off between labor utilization (Equation (4)) and farm net profit (Equation (5)):

$$
\text { Maximize } J(x)=(1-\alpha)\left(\operatorname{LUF}(x)^{\prime}\right)+(\alpha)\left(\operatorname{ATNP}(x)^{\prime}\right)
$$

$\alpha=$ weighting variable in the range [0,1], $\operatorname{LUF}(x)^{\prime}-$ Normalized labor utilization function using $x$ decision variables, and ATNP $(x)^{\prime}$-Normalized farm net profit using $x$ decision variables. 
The weighted objective function $K(x)$ describes the trade-off between labor utilization (Equation (4)) and farm electricity related $\mathrm{CO}_{2}$ emissions (Equation (6)):

$$
\text { Maximize } K(x)=(1-\alpha)\left(\operatorname{LUF}(x)^{\prime}\right)+(\alpha)\left(\operatorname{CE}(x)^{\prime}\right)
$$

$\alpha=$ weighting variable in the range $[0,1], \operatorname{LUF}(x)^{\prime}-$ Normalized labor utilization function using $x$ decision variables, and $\mathrm{CE}(x)^{\prime}-$ Normalized farm electricity related $\mathrm{CO}_{2}$ emissions using $x$ decision variables.

$\operatorname{LUF}(x)^{\prime}, \operatorname{ATNP}(x)^{\prime}$ and CE(x)' were computed using Equations (9)-(11).

$$
\operatorname{LUF}(x)^{\prime}=\frac{\operatorname{LUF}(x)-L U F_{\text {min }}}{L U F_{\text {max }}-L U F_{\text {min }}}
$$

where $\operatorname{LUF}(x)$-Labor utilization function using $x$ decision variables, $L U F_{\text {max }}$-Maximum LUF value, and $L U F_{\text {min }}$-Minimum LUF value.

$$
\operatorname{ATNP}(x)^{\prime}=\frac{\operatorname{ATNP}(x)-A T N P_{\text {min }}}{A T N P_{\text {max }}-A T N P_{\text {min }}}
$$

where $\operatorname{ATNP}(x)$-Average after-tax net profit using $x$ decision variables, $A T N P_{\max }$ Maximum ATNP value, and $A T N P_{\min }$-Minimum ATNP value.

$$
C E(x)^{\prime}=1-\frac{C E(x)-C E_{\text {min }}}{C E_{\max }-C E_{\text {min }}}
$$

where $C E(x)$-Average annual farm electricity related $\mathrm{CO}_{2}$ emissions using $x$ decision variables, $C E_{\max }$-Maximum $C E$ value, and $C E_{\text {min }}-$ Minimum $C E$ value.

Decision variables were defined by a vector of integer values. A Genetic Algorithm (GA) was utilized to obtain the vector of decision variables to maximize $\mathrm{J}(\mathrm{x})$ or $\mathrm{K}(\mathrm{x})$ for 101 values of $\alpha$ between 0 and 1, using increments of 0.01 .

Constraints were as follows:

$$
T_{w h} \leq M T_{e}+E M D-W H D
$$

where $T_{w h}$-Start time for water heating timer, $M T_{e}$-Evening milking start time, EMDMaximum duration per day for evening milking (hours), and WHD-Maximum duration per day for water heating (hours).

$$
M T_{e}-M T_{m} \geq 8
$$

where $M T_{e}$-Evening milking start time, and $M T_{m}$-Morning milking start time.

The implementation of GA in this paper as well as the parameters used have previously been described in Breen et al. [24].

\subsubsection{Case Study}

The case study used in this paper was previously employed in Upton et al. [25] and Breen et al. [6,23,24]: a 195 cow spring calving dairy farm with annual milk yield of 774,089 L. Two scenarios were investigated, namely Scenarios A and B:

- $\quad$ Scenario A employed weighted objective function $J(x)$ (Equation (7)), i.e., multiobjective optimization of labor utilization and farm net profit.

- Scenario B employed weighted objective function $K(x)$ (Equation (8)), i.e., multiobjective optimization of labor utilization and farm electricity related $\mathrm{CO}_{2}$ emissions.

The time horizon employed for the two scenarios was 10 years. The price of gas, oil, electricity and milk did not vary during those ten years. Oil was $€ 0.075 / \mathrm{kWh}$, gas was $€ 0.07 / \mathrm{kWh}$, milk was $€ 0.33 / \mathrm{L}$ and electricity was $€ 0.10 / \mathrm{kWh}$ from 00:00 to 09:00 and $€ 0.18 / \mathrm{kWh}$ from 09:00 to 00:00 [26]. 


\section{Results \\ Multi-Objective Optimization Results}

The results for Scenario A are displayed in Table 1. When values of $\alpha$ between 0 and 0.66 inclusive were used, the optimal morning and evening milking start times were 07:00 and 17:00, respectively. The ATNP was $€ 61,704$, the LUF was $100 \%$ and the electricity related $\mathrm{CO}_{2}$ emissions (CE) were $14,285 \mathrm{~kg}$. When $\alpha$ values between 0.67 and 0.88 inclusive were used, the optimal morning and evening milking start times were 06:00 and 17:00, respectively. The ATNP was $€ 61,811$, the LUF was $50 \%$ and the CE were $14,269 \mathrm{~kg}$. When $\alpha$ values between 0.89 and 1 inclusive were used, the optimal morning and evening milking start times were $06: 00$ and 20:00, respectively. The ATNP was $€ 61,841$, the LUF was $0 \%$ and the CE were $14,094 \mathrm{~kg}$.

The results for Scenario B are displayed in Table 2. When values of $\alpha$ between 0 and 0.48 inclusive were used, the optimal morning and evening milking start times were 07:00 and 17:00, respectively. The CE were $14,285 \mathrm{~kg}$, the LUF was $100 \%$ and the ATNP was $€ 61,704$. When $\alpha$ values between 0.49 and 0.83 inclusive were used, the optimal morning and evening milking start times were 07:00 and 19:00, respectively. The CE were $9677 \mathrm{~kg}$, the LUF was $55 \%$ and the ATNP was $€ 61,285$. When $\alpha$ values between 0.84 and 1 inclusive were used, the optimal morning and evening milking start times were 06:00 and 20:00, respectively. The CE were $3815 \mathrm{~kg}$, the LUF was $0 \%$ and the ATNP was $€ 59,017$.

Table 1. Scenario A results. The optimal decision variables are shown for a range of $\alpha$ values. The corresponding labor utilization function (LUF), after-tax net profit (ATNP) and electricity related $\mathrm{CO}_{2}$ emissions (CE) are also shown.

\begin{tabular}{|c|c|c|c|}
\hline & $\begin{array}{c}100 \% \text { LUF } \\
\text { Optimization }\end{array}$ & & $\begin{array}{c}100 \% \text { ATNP } \\
\text { Optimization }\end{array}$ \\
\hline$\alpha$ & $0-0.66$ & $0.67-0.88$ & $0.89-1$ \\
\hline Morning milking start time & 07:00 & 06:00 & 06:00 \\
\hline Evening milking start time & $17: 00$ & $17: 00$ & 20:00 \\
\hline Milk cooling system & DX & DX & DX \\
\hline Ice bank start time & $\mathrm{N} / \mathrm{A}$ & $\mathrm{N} / \mathrm{A}$ & $\mathrm{N} / \mathrm{A}$ \\
\hline Pre-cooling & YES & YES & YES \\
\hline Water heating system & ELECTRIC & ELECTRIC & ELECTRIC \\
\hline Water heating timer & YES & YES & YES \\
\hline Timer start time (load shifting) & 00:00 & 00:00 & 00:00 \\
\hline VSD & NO & $\mathrm{NO}$ & $\mathrm{NO}$ \\
\hline RS & NONE & NONE & NONE \\
\hline Annual ATNP $(€)$ & 61,704 & 61,811 & 61,841 \\
\hline Annual CE (kg) & 14,285 & 14,269 & 14,094 \\
\hline Labor utilization function (\%) & 100 & 50 & 0 \\
\hline
\end{tabular}


Table 2. Scenario B results. The optimal decision variables are shown for a range of $\alpha$ values. The corresponding labor utilization function (LUF), electricity related $\mathrm{CO}_{2}$ emissions (CE) and after-tax net profit (ATNP) are also shown.

\begin{tabular}{|c|c|c|c|}
\hline & $\begin{array}{c}100 \% \text { LUF } \\
\text { Optimization }\end{array}$ & & $\begin{array}{c}100 \% \mathrm{CO}_{2} \\
\text { Optimization }\end{array}$ \\
\hline$\alpha$ & $0-0.48$ & $0.49-0.83$ & $0.84-1$ \\
\hline Morning milking start time & 07:00 & 07:00 & 06:00 \\
\hline Evening milking start time & $17: 00$ & 19:00 & $20: 00$ \\
\hline Milk cooling system & DX & DX & DX \\
\hline Ice bank start time & $\mathrm{N} / \mathrm{A}$ & $\mathrm{N} / \mathrm{A}$ & $\mathrm{N} / \mathrm{A}$ \\
\hline Pre-cooling & YES & YES & YES \\
\hline Water heating system & ELECTRIC & GAS & GAS \\
\hline Water heating timer & YES & $\mathrm{N} / \mathrm{A}$ & $\mathrm{N} / \mathrm{A}$ \\
\hline Timer start time (load shifting) & 00:00 & $\mathrm{N} / \mathrm{A}$ & $\mathrm{N} / \mathrm{A}$ \\
\hline VSD & $\mathrm{NO}$ & YES & YES \\
\hline RS & NONE & NONE & PV $(11 \mathrm{~kW}$ p $)$ \\
\hline Annual CE (kg) & 14,285 & 9677 & 3815 \\
\hline Annual ATNP $(€)$ & 61,704 & 61,285 & 59,017 \\
\hline Labor utilization function (\%) & 100 & 55 & 0 \\
\hline
\end{tabular}

\section{Discussion}

For Scenario A, if the weighted objective function was fully weighted towards farm net profit, the optimal milking start times consisted of the earliest possible morning milking start time (06:00) and the latest possible evening milking start time (20:00). This agreed with the results of Breen et al. [6], in which purely financial optimization was performed for the same case study. It is unlikely that farmers would consider these milking start times as they were the furthest away from normal practice based on the data collected in Section 2.2.1. If the weighted objective function was fully weighted towards the LUF, the optimal milking start times changed to the most common start times (07:00 and 17:00). The increase in annual net profit when changing from the most common to least common milking start times was $€ 137$, with no other infrastructure setup or management changes taking place. A corresponding decrease in electricity related $\mathrm{CO}_{2}$ emissions of $191 \mathrm{~kg}$ was also observed. This increase in profit and decrease in emissions is unlikely to entice farmers to carry out milking at 6:00 in the morning and 20:00 in the evening. If farmers were to adjust their morning milking start time to 6:00 only, they would incur savings of $€ 107$ per year, which would be $78 \%$ of the savings incurred by changing both their morning and evening milking start times.

Despite the potential inclusion of three different types of renewable system, namely $\mathrm{PV}$, solar thermal water heating and heat recovery systems, none were included in any of the optimization results for Scenario A. These results agree with previous research which deduced that these renewables were not financially feasible in a dairy farm context without external grant incentives [27-29]. Importantly, these results also indicate that altering milking start times does not improve the financial feasibility of renewable technologies on farms.

For Scenario B, when the weighted objective function was fully weighted towards farm electricity related $\mathrm{CO}_{2}$ emissions the optimal milking start times were 06:00 and 20:00, as was the case when maximizing net profit in Scenario A. Again farmers would be unlikely to consider these milking start times since they deviate furthest from normal operations. If the weighted objective function was fully weighted towards LUF the optimal milking start times changed to 07:00 and 17:00, which was also seen in Scenario A. The decrease in annual farm electricity related $\mathrm{CO}_{2}$ emissions when changing from the most to least common milking start times was $10,470 \mathrm{~kg}$, A corresponding decrease in profit of $€ 2687$ was also observed. However, these decreases in emissions and profit also involved changing the water heating system from electric to gas and adding VSDs and an $11 \mathrm{kWp}$ $\mathrm{PV}$ system to the farm. Most of the reduction in emissions and profit stemmed from using 
a different water heating system and adding the VSDs and PV system. This has been discussed previously in Breen et al. [23,24]. If the milking start times were not altered but the infrastructure setup changes were implemented, the decrease in emissions would be $10,277 \mathrm{~kg}$, while the decrease in profit would be $€ 2648$. Hence, the changing of milking start times only accounts for a reduction of $193 \mathrm{~kg}$ in emissions and $€ 39$ in profit.

Based on the results of Scenario A and B, it is possible to simultaneously increase farm profitability and reduce farm electricity related $\mathrm{CO}_{2}$ emissions simply by using early morning and late evening milking start times. This was previously reported by Upton et al. [4]. However, in this study it has been established that early morning milking start times and late evening milking start times are not commonly used. From the perspective of the farmer, the monetary benefits of switching to these milking start times is relatively poor. Morris et al. [30] found that profitability is a key metric in assessing the applicability of innovations on the farm, hence the adoption of the changes discussed here is unlikely to be considered. The environmental benefits are also relatively poor unless the change in milking start times is accompanied by the purchase of new infrastructure. Hence, it is likely that the drawback of having to change the farmer's working routine would greatly outweigh the associated environmental benefit.

Previous studies by O'Connell et al. [31] and Remond et al. [7] investigated the effect of milking routines on animal behavior and milk production. Remond et al. found that unless the time between morning and evening milking start times was reduced to five hours or less, there were no significant reductions in milk production. No such scenarios were considered in this study. Changes in animal behavior and milk production are not of immediate relevance for further study in the context of this paper as the monetary and environmental benefits of changing milking start times are relatively poor.

While it was found that altering milking start times provided little monetary benefit to farmers, future electricity tariffs were not considered. Future tariffs may offer greater financial incentives for using electricity during off-peak hours, thereby increasing monetary gains for farmers using earlier morning milking start times and later evening milking start times. Future work could incorporate such tariffs in order to quantify the associated monetary benefits to farmers. Furthermore, the electricity related $\mathrm{CO}_{2}$ emissions used for calculations in this work did not consider marginal emissions. Future work could consider marginal emissions which may provide a more accurate representation of the environmental benefits associated with altering milking start times.

\section{Conclusions}

- Multi-objective optimization of milking start times and farm infrastructure setup was carried out in this study in order to assess trade-offs between labor utilization, net profit and electricity related $\mathrm{CO}_{2}$ emissions on dairy farms.

- It was found that the most common morning and evening milking start times were 07:00 and 17:00, respectively, while the least common morning and evening milking start times were 06:00 and 20:00, respectively.

- For a 195 cow farm case study, using the least common milking start times maximized farm net profit and minimized farm electricity related $\mathrm{CO}_{2}$ emissions.

- When optimizing labor utilization and net profit, annual monetary savings of $€ 137$ and a reduction of $191 \mathrm{~kg}$ in electricity related $\mathrm{CO}_{2}$ emissions were realized upon changing the farm's milking start times from the most common to the least common.

- When optimizing labor utilization and electricity related $\mathrm{CO}_{2}$ emissions, a reduction in electricity related $\mathrm{CO}_{2}$ emissions of $10,470 \mathrm{~kg}$ and a decrease in net profit of $€ 2687$ were seen upon changing the farm's milking start times from the most common to the least common. However, this was due in large part to the addition of energy efficient and renewable technologies to the farm, rather than the changing of milking start times.

- The financial and environmental benefits of changing from the most common milking start times to the least common milking start times were relatively poor. 
Author Contributions: Conceptualization, M.B., M.D.M. and J.U.; methodology, M.B.; software, M.B.; writing—original draft preparation, M.B.; writing—review and editing, M.B., M.D.M. and J.U.; visualization, M.B.; supervision, M.D.M. and J.U. All authors have read and agreed to the published version of the manuscript.

Funding: This research was funded by Teagasc.

Institutional Review Board Statement: Not applicable.

Informed Consent Statement: Not applicable.

Data Availability Statement: Data sharing not applicable.

Conflicts of Interest: The authors declare no conflict of interest.

\section{References}

1. Central Statistics Office. Milk Statistics. 2021. Available online: https://data.cso.ie/product/MS (accessed on 25 April 2021).

2. DAFM. Ag Climatise: A Roadmap towards Climate Neutrality 2020. Available online: https://www.gov.ie/en/publication/07 fbe-ag-climatise-a-roadmap-towards-climate-neutrality / (accessed on 25 April 2021).

3. Upton, J.; Murphy, M.; Shalloo, L.; Koerkamp, P.G.; De Boer, I. A mechanistic model for electricity consumption on dairy farms: Definition, validation, and demonstration. J. Dairy Sci. 2014, 97, 4973-4984. [CrossRef] [PubMed]

4. Upton, J.; Murphy, M.; Shalloo, L.; Koerkamp, P.G.; de Boer, I. Assessing the impact of changes in the electricity price structure on dairy farm energy costs. Appl. Energy 2015, 137, 1-8. [CrossRef]

5. Upton, J.; Breen, M. Milking time distributions on Irish dairy farms. In Proceedings of the International Agriculture Workforce Conference, Cork, Ireland, 10 July 2018; pp. 51-56.

6. Breen, M.; Upton, J.; Murphy, M. Development of a discrete infrastructure optimization model for economic assessment on dairy farms (DIOMOND). Comput. Electron. Agric. 2019, 156, 508-522. [CrossRef]

7. Rémond, B.; Pomiès, D.; Julien, C.; Guinard-Flament, J. Performance of dairy cows milked twice daily at contrasting intervals. Animal 2009, 3, 1463-1471. [CrossRef] [PubMed]

8. Pahl, C.; Hartung, E.; Mahlkow-Nerge, K.; Haeussermann, A. Feeding characteristics and rumination time of dairy cows around estrus. J. Dairy Sci. 2015, 98, 148-154. [CrossRef]

9. Beerda, B.; Ouweltjes, W.; Šebek, L.; Windig, J.; Veerkamp, R. Effects of Genotype by Environment Interactions on Milk Yield, Energy Balance, and Protein Balance. J. Dairy Sci. 2007, 90, 219-228. [CrossRef]

10. Vanbergue, E.; Peyraud, J.L.; Ferlay, A.; Miranda, G.; Martin, P.; Hurtaud, C. Effects of feeding level, type of forage and milking time on milk lipolytic system in dairy cows. Livest. Sci. 2018, 217, 116-126. [CrossRef]

11. Ambord, S.; Bruckmaier, R. Milk flow-dependent vacuum loss in high-line milking systems: Effects on milking characteristics and teat tissue condition. J. Dairy Sci. 2010, 93, 3588-3594. [CrossRef]

12. Amos, H.; Kiser, T.; Loewenstein, M. Influence of Milking Frequency on Productive and Reproductive Efficiencies of Dairy Cows. J. Dairy Sci. 1985, 68, 732-739. [CrossRef]

13. Herve, L.; Quesnel, H.; Lollivier, V.; Portanguen, J.; Bruckmaier, R.; Boutinaud, M. Mammary epithelium disruption and mammary epithelial cell exfoliation during milking in dairy cows. J. Dairy Sci. 2017, 100, 9824-9834. [CrossRef]

14. Di Somma, M.; Yan, B.; Bianco, N.; Graditi, G.; Luh, P.; Mongibello, L.; Naso, V. Multi-objective design optimization of distributed energy systems through cost and exergy assessments. Appl. Energy 2017, 204, 1299-1316. [CrossRef]

15. Fan, Y.; Xia, X. A multi-objective optimization model for energy-efficiency building envelope retrofitting plan with rooftop PV system installation and maintenance. Appl. Energy 2017, 189, 327-335. [CrossRef]

16. García-Villalobos, J.; Zamora, I.; Knezović, K.; Marinelli, M. Multi-objective optimization control of plug-in electric vehicles in low voltage distribution networks. Appl. Energy 2016, 180, 155-168. [CrossRef]

17. Jubril, A.; Olaniyan, O.; Komolafe, O.; Ogunbona, P. Economic-emission dispatch problem: A semi-definite programming approach. Appl. Energy 2014, 134, 446-455. [CrossRef]

18. Hou, J.; Sun, J.; Hofmann, H. Control development and performance evaluation for battery/flywheel hybrid energy storage solutions to mitigate load fluctuations in all-electric ship propulsion systems. Appl. Energy 2018, 212, 919-930. [CrossRef]

19. Karmellos, M.; Kiprakis, A.; Mavrotas, G. A multi-objective approach for optimal prioritization of energy efficiency measures in buildings: Model, software and case studies. Appl. Energy 2015, 139, 131-150. [CrossRef]

20. Ma, T.; Yang, H.; Lu, L. Solar photovoltaic system modeling and performance prediction. Renew. Sustain. Energy Rev. 2014, 36, 304-315. [CrossRef]

21. Raza, S.S.; Janajreh, I.; Ghenai, C. Sustainability index approach as a selection criteria for energy storage system of an intermittent renewable energy source. Appl. Energy 2014, 136, 909-920. [CrossRef]

22. Yang, J.; He, L.; Fu, S. An improved PSO-based charging strategy of electric vehicles in electrical distribution grid. Appl. Energy 2014, 128, 82-92. [CrossRef]

23. Breen, M.; Upton, J.; Murphy, M. Photovoltaic systems on dairy farms: Financial and renewable multi-objective optimization (FARMOO) analysis. Appl. Energy 2020, 278, 115534. [CrossRef] 
24. Breen, M.; Murphy, M.; Upton, J. Development of a dairy multi-objective optimization (DAIRYMOO) method for economic and environmental optimization of dairy farms. Appl. Energy 2019, 242, 1697-1711. [CrossRef]

25. Upton, J.; Murphy, M.; de Boer, I.; Koerkamp, P.G.; Berentsen, P.; Shalloo, L. Investment appraisal of technology innovations on dairy farm electricity consumption. J. Dairy Sci. 2015, 98, 898-909. [CrossRef] [PubMed]

26. SEAI. Domestic Fuel Cost Comparison. 2021. Available online: https://www.seai.ie/publications/Domestic-Fuel-CostComparison.pdf (accessed on 5 May 2021).

27. Nacer, T.; Hamidat, A.; Nadjemi, O.; Bey, M. Feasibility study of grid connected photovoltaic system in family farms for electricity generation in rural areas. Renew. Energy 2016, 96, 305-318. [CrossRef]

28. Carpenter, J.; Vallis, E.; Vranch, A. Performance of a UK dairy solar water heater. J. Agric. Eng. Res. 1986, 35, 131-139. [CrossRef]

29. Morison, K.; Gregory, W.; Hooper, R. Improving Dairy Shed Energy Efficiency: Technical Report; CAENZ: Christchurch, New Zealand, 2007. Available online: https://ir.canterbury.ac.nz/bitstream/handle/10092/11588/Dairy_Technical_Report.pdf;sequence=1 (accessed on 21 March 2021).

30. Morris, C.; Loveridge, A.; Fairweather, J. Understanding Why Farmers Change Their Farming Practices: The Role of Orienting Principles in Technology Transfer; Agribusiness \& Economics Research Unit: Canterbury, New Zealand, 1995.

31. O'Connell, J.; Giller, P.S.; Meaney, W. A Comparison of Dairy Cattle Behavioural Patterns at Pasture and during Confinement. Irish J. Agric. Res. 1989, 28, 65-72. 